\title{
Causes of stillbirths and neonatal deaths in Dhanusha district, Nepal: A verbal autopsy study
}

\author{
Manandhar SR 1 , Ojha A ${ }^{1}$, Manandhar DS², Shrestha B ${ }^{2}$, Shrestha $D^{2}$, Saville $\mathbf{N}^{3}$, Costello AM ${ }^{3}$, Osrin D $^{3}$ \\ ${ }^{1}$ Department of Paediatrics, Kathmandu Medical College, Sinamangal, ${ }^{2}$ Mother and Infant Research Activities \\ (MIRA), Nepal, ${ }^{3}$ UCL Centre for International Health and Development, Institute of Child Health, London, UK
}

\begin{abstract}
Background: Perinatal (stillbirths and first week neonatal deaths) and neonatal (deaths in the first 4 weeks) mortality rates remain high in developing countries like Nepal. As most births and deaths occur in the community, an option to ascertain causes of death is to conduct verbal autopsy.

Objective: The objective of this study was to classify and review the causes of stillbirths and neonatal deaths in Dhanusha district, Nepal.

Materials and Methods: Births and neonatal deaths were identified prospectively in 60 village development committees of Dhanusha district. Families were interviewed at six weeks after delivery, using a structured questionnaire. Cause of death was assigned independently by two pediatricians according to a predefined algorithm; disagreement was resolved in discussion with a consultant neonatologist.

Results: There were 25,982 deliveries in the 2 years from September 2006 to August 2008. Verbal autopsies were available for $601 / 813$ stillbirths and $671 / 954$ neonatal deaths. The perinatal mortality rate was 60 per 1000 births and the neonatal mortality rate 38 per 1000 live births. $84 \%$ of stillbirths were fresh and obstetric complications were the leading cause (67\%). The three leading causes of neonatal death were birth asphyxia (37\%), severe infection (30\%) and prematurity or low birth weight (15\%). Most infants were delivered at home $(65 \%), 28 \%$ by relatives. Half of women received an injection (presumably an oxytocic) during home delivery to augment labour. Description of symptoms commensurate with birth asphyxia was commoner in the group of infants who died (41\%) than in the surviving group $(14 \%)$.

Conclusion: The current high rates of stillbirth and neonatal death in Dhanusha suggest that the quality of care provided during pregnancy and delivery remains sub-optimal. The high rates of stillbirth and asphyxial mortality imply that, while efforts to improve hygiene need to continue, intrapartum care is a priority. A second area for consideration is the need to reduce the uncontrolled use of oxytocic for augmentation of labour.
\end{abstract}

Key words: Stillbirth, neonatal death, verbal autopsy, Nepal.

$\mathrm{S}_{\mathrm{s}}^{\mathrm{t}}$ tillbirths and neonatal deaths remain common in many low-income countries. Nepal's most recent estimates of perinatal mortality rate (PMR: stillbirths and first week deaths) and neonatal mortality rate (NMR: deaths in the first four weeks) are 45 per 1000 births and 33 per 1000 live births, respectively ${ }^{1}$. About $80 \%$ of deliveries in Nepal occur at home and only $19 \%$ are conducted by health personnel ${ }^{1}$. Over the last 15 years, Nepal's infant mortality rate (IMR: deaths in the first year) has fallen from 82 to 48 per 1000 live births ${ }^{1}$. This is at least partly due to programmes conducted through government and other organizations, including those for acute respiratory infections and diarrhoeal diseases. There were no such programmes to reduce perinatal and neonatal deaths in Nepal, and their share of the overall figures has increased. If we are to reduce stillbirths and neonatal deaths, we need to know their causes. However, clinical registration of cause of death is available for less than a third of global newborn deaths ${ }^{2}$. When families do not seek hospital care and medical records are unavailable, trying to understand the cause of death from their accounts of illness is the only option. Verbal autopsy is a method of ascribing causes of death on the basis of information on events, signs and symptoms supplied by the deceased's caretakers ${ }^{3,4,5}$. Procedures for infant and child deaths have developed over the last twenty years, ${ }^{6,7,8,9,10,11,12}$ and verbal autopsy has been used in studies, ${ }^{13,14,15}$ in sample registration systems in India, and as part of the INDEPTH network of demographic surveillance sites ${ }^{16}$.

\section{Correspondence}

Dr. Sunil Raja Manandhar

Lecturer, Department of Paediatrics

Kathmandu Medical College

E-mail: drsunilraja@gmail.com 
Because there is no gold standard with which to compare the findings, misclassification of causes of death is possible ${ }^{17}$. Occasionally, medical records are available and a process of triangulation can take place; or interviews with families whose children died in hospital can be compared with case notes and hospital records, even though the case-mix seen in hospitals is likely to differ from the pattern of illness in communities. There are several possible approaches to data collection. An interviewer (often with a non-medical background) may discuss the events that preceded death with a child's mother or family and record the narrative in open-ended form. Alternatively, a series of closed questions may be asked, designed to establish the presence or absence of particular signs and symptoms, or particular health care actions ${ }^{18,19}$. At the analytical stage, the narrative or closed questions are read and classified by a clinician. The development of algorithms to aid this process has led to the idea of using computer analysis to classify cause of death, but this is not yet routine ${ }^{20,21}$.

Mother and Infant Research Activities (MIRA) is a non-government organisation (NGO) established to improve the health of mothers and newborn infants through research, training and advocacy. MIRA has conducted several community-based studies, including a trial of community mobilisation through women's groups in Makwanpur district, which showed a 30\% reduction in neonatal mortality ${ }^{22}$. A similar study, with some modifications, is being conducted in Dhanusha district in the southern plains of Nepal. In the course of the study, stillbirths and neonatal deaths were identified in a surveillance population of around 420 000 and 1272 verbal autopsies were collected from 60 village development committees ${ }^{24}$. The objective of this analysis was to classify and review the causes of stillbirths and neonatal deaths in the study area.

\section{Materials and methods}

\section{Setting}

Dhanusha is situated in the south-eastern region of Nepal and covers an area of $1180 \mathrm{~km}^{2}$ with a population of around $777000^{23}$. In a study population of around 420 000 , there are approximately 55800 married women of reproductive age and around 14000 annual births ${ }^{24}$. The literacy rate is $56 \%$ and $89 \%$ of people live in rural $\operatorname{areas}^{23}$. The district's PMR is 63 per 1000 births and it's NMR 34 per 1000 live births ${ }^{24}$.

\section{Procedures}

This was a prospective study that formed part of a major child survival study using women's groups to improve maternal and newborn health. Out of 101 village development committees (VDCs) in Dhanusha, after exclusion of 9 severely politically affected VDCs and 13 VDCs with populations of less than 4000, 60 were selected randomly for inclusion. After mapping, households were identified and data collected over two years. Each village development committee has an average population of around 8,000. In each, selected key informants provided information prospectively about every birth and death to village development committee interviewers. The interviewers verified each event and visited families at six weeks after delivery to administer a questionnaire. In the event of a stillbirth or neonatal death, they visited within three months to administer a verbal autopsy. The study was explained to participants and consent taken. We used a verbal autopsy tool which combined open-ended narrative with closed questions and was developed in light of other tools: the original WHO infant verbal autopsy ${ }^{25}$, a tool updated in 2002 by the INDEPTH network, and a new tool in development (WHO/JHU/AKU/SNL 11/05/2003). Confidentiality was maintained by interviewing individuals or family groups separately and not discussing the matter openly.

\section{Analytical methods}

Questionnaires were entered in an electronic database in Microsoft Access (Microsoft Corporation). We based our classification of cause of death on the Neonatal and Intrauterine Death classification according to Etiology $(\mathrm{NICE})^{26}$, and the WHO Neonatal Child Health Epidemiology Reference Group (CHERG) ${ }^{27}$. Narratives and responses to closed questions were reviewed independently by two pediatricians (SRM and AO). Cause of death was classified according to the algorithm shown in Box 1. Cases in which the two paediatricians did not agree were discussed with a consultant neonatologist (DSM) and a final diagnosis was assigned by consensus. Further analysis was carried out in SPSS 11.5 (SPSS Inc., Illinois). The findings are presented as frequencies and proportions.

\section{Ethical issues}

Study approval was obtained from the Nepal Health Research Council (NHRC), the ethical committee of Great Ormond Street Hospital and the Institute of Child Health and the Social Welfare Council of Nepal. Informed consent in local or Nepali languages was obtained from respondents prior to interview. No data used in the analysis contained the names of participants.

\section{Results}

Data were collected over two years from $1^{\text {st }}$ September 2006 to $31^{\text {st }}$ August 2008. There were 25982 deliveries in this period, with 813 stillbirths and 954 neonatal deaths. Verbal autopsies were available for 601 stillbirths and 671 neonatal deaths ( $72 \%$ of all). Reasons for missing autopsies included political conflict and instability in the district, transportation problems and absence of male 
head of household to give permission for interview. Information on stillbirths, early and late neonatal deaths is presented in Table 1 . The study PMR was 60 per 1000 births and the NMR 38 per 1000 live births. Deaths were slightly more common in male infants $(56 \%)$ and most of the infants were born at term $(76 \%)$.

The classification of cause of death is presented in Table 2. Of 601 stillbirths, 504 (84\%) were fresh and $97(16 \%)$ macerated. Obstetric complications were the leading cause $(67 \%)$, followed by prematurity $(10 \%)$. $10 \%$ of perinatal deaths were unclassifiable on the basis of the questionnaire. Among neonatal deaths, 529 (79\%) were early and $142(21 \%)$ late. The three leading causes of neonatal deaths were birth asphyxia (37\%), severe infection $(30 \%)$ and prematurity or low birth weight $(15 \%)$.

Table 3 summarises characteristics of delivery. Most of the infants $(65 \%)$ were delivered at home. Many deliveries were conducted by relatives (28\%), and only $26 \%$ were assisted by doctors. $20 \%$ were conducted by village practitioners who are untrained health workers. It is interesting to note that $50 \%$ of women received an injection (presumably of an oxytocic drug, Oxytocin) during home delivery to augment labour. Among neonatal deaths, 886 (74\%) infants were reported by their mothers as being of normal size. In $53 \%$ of births, the umbilical cord was cut with unsterilised instruments, and dung or ash was applied to the cut end of the cord in $20 \%$ of cases. Nearly a third of infants were not fed anything within half an hour of birth and $23 \%$ were given goat's milk as the first feed.
Table 4 examines the circumstances of presumptive birth asphyxia and resuscitation. Among neonatal deaths, $41 \%$ of infants did not cry immediately after birth and some attempt at resuscitation was made in $90 \%$ of cases. Half of the infants with presumptive birth asphyxia did not cry at all. The commonest resuscitative measure was mouth-to-mouth respiration (49\%). In terms of treatment in general - not only for birth asphyxia - 365 $(56 \%)$ of 646 infants who died in the neonatal period did not receive any form of treatment. The main reasons given for this were poverty, unavailability of a male family member who could take a decision in time, and an assumption that infants would not survive. Of the $44 \%$ of infants who did receive treatment, 244 (88\%) were seen by allopathic health care providers: 106 (38\%) at hospitals, $63(23 \%)$ at other institutions such as nursing homes and clinics, and $75(27 \%)$ at home. $35(12 \%)$ received treatment from providers such as traditional healers (jhankri) and herbalists.

Table 5 compares some of the characteristics of infants who died with those of infants who survived. Out of 25,169 surviving infants, information was available on 17,377 (69\%). Migration of mothers to neighbouring districts, transportation problems and political conflicts were the main reasons for missing data. $1 \%$ of infants were preterm in the surviving group, compared to $24 \%$ in the group who survived. Village practitioners delivered $6 \%$ of infants in the group who survived, and $19 \%$ of those who died. Description of symptoms of birth asphyxia was commoner in the group who died $(41 \%)$ than in the surviving group (14\%).

Table 1: Births, stillbirths and neonatal deaths in 60 village development committees of Dhanusha district, 2006-2008

\begin{tabular}{|l|c|}
\hline Category & Frequency \\
\hline Births & 25982 \\
\hline Stillbirths & 813 \\
\hline Live births & 25169 \\
\hline Neonatal deaths & 954 \\
\hline Early neonatal deaths & 760 \\
\hline Late neonatal deaths & 194 \\
\hline Perinatal deaths (stillbirths and early neonatal deaths) & 1573 \\
\hline Stillbirths classified on the basis of verbal autopsy & 601 \\
\hline Neonatal deaths classified on the basis of verbal autopsy & 671 \\
\hline Indicator & Rate \\
\hline Stillbirth Rate per 1000 births & 31 \\
\hline Neonatal Mortality Rate per 1000 live births & 38 \\
\hline Early Neonatal Mortality Rate per 1000 live births & 30 \\
\hline Late Neonatal Mortality Rate per 1000 live births & 8 \\
\hline Perinatal Mortality Rate per 1000 births & 60 \\
\hline
\end{tabular}


Table 2: Causes of stillbirth and neonatal death in 60 village development committees of Dhanusha district, 20062008

\begin{tabular}{|l|c|c|}
\hline Stillbirth & Frequency & (\%) \\
\hline Obstetric complications & 403 & $(67)$ \\
\hline Prematurity & 63 & $(10)$ \\
\hline Maternal specific conditions & 41 & $(7)$ \\
\hline Congenital malformations & 16 & $(3)$ \\
\hline Multiple pregnancy & 10 & $(2)$ \\
\hline Others & 9 & $(1)$ \\
\hline Unclassifiable & 59 & $(10)$ \\
\hline Total & $\mathbf{6 0 1}$ & $(\mathbf{1 0 0})$ \\
\hline Neonatal death & & \\
\hline Birth asphyxia & 250 & $(37)$ \\
\hline Severe infection & 205 & $(30)$ \\
\hline Prematurity or low birth weight & 101 & $(15)$ \\
\hline Hypothermia & 45 & $(7)$ \\
\hline Congenital malformations & 6 & $(1)$ \\
\hline Others & 33 & $(5)$ \\
\hline Unclassifiable & 31 & $(5)$ \\
\hline Total & $\mathbf{6 7 1}$ & $\mathbf{1 0 0}$ \\
\hline
\end{tabular}

Table 3: Characteristics of delivery for 1272 stillbirths and neonatal deaths in 60 village development committees of Dhanusha district, 2006-2008

\begin{tabular}{|l|c|c|}
\hline Place of delivery & Frequency & (\%) \\
\hline Home & 826 & $(65)$ \\
\hline Hospital & 254 & $(20)$ \\
\hline Other health institution (primary health centre, private clinic) & 145 & $(12)$ \\
\hline On the way to hospital & 30 & $(2)$ \\
\hline Other & 17 & $(1)$ \\
\hline Total & $\mathbf{1 2 7 2}$ & $(\mathbf{1 0 0})$ \\
\hline Delivery conducted by & & \\
\hline Relative & 360 & $(28)$ \\
\hline Doctor & 341 & $(27)$ \\
\hline Village practitioner $^{1}$ & 241 & $(19)$ \\
\hline Health worker & \\
\hline Volunteer & \\
\hline Other (friend, neighbor) & 161 & $(13)$ \\
\hline Alone & 105 & $(8)$ \\
\hline Total & 14 & $(1)$ \\
\hline History of Injection given to mother & 50 & $(4)$ \\
\hline Yes & $\mathbf{1 2 7 2}$ & $(\mathbf{1 0 0})$ \\
\hline No & & \\
\hline Total & 628 & $(50)$ \\
\hline Umbilical cord cutting instrument & 640 & $(50)$ \\
\hline Unboiled instrument & $\mathbf{1 2 6 8}$ & $(\mathbf{1 0 0})$ \\
\hline Boiled blade & & \\
\hline
\end{tabular}


Table 3 cont...

\begin{tabular}{|l|c|c|}
\hline Other & 10 & $(1)$ \\
\hline Unable to recall & 180 & $(28)$ \\
\hline Total & $\mathbf{6 5 3}$ & $(\mathbf{1 0 0})$ \\
\hline Umbilical stump application & & \\
\hline Nothing applied & 240 & $(37)$ \\
\hline Others (dung or ash) & 134 & $(21)$ \\
\hline Oil & 28 & $(4)$ \\
\hline Antiseptic (Dettol) & 23 & $(3)$ \\
\hline Unable to recall & 228 & $(35)$ \\
\hline Total & $\mathbf{6 5 3}$ & $(\mathbf{1 0 0})$ \\
\hline Infant's first feed & & \\
\hline No prelacteal feeds & 203 & $(30)$ \\
\hline Goat's milk & 155 & $(23)$ \\
\hline Prelacteal (Honey, sugar, clarified butter) & 112 & $(17)$ \\
\hline Mother's breast milk & 80 & $(12)$ \\
\hline Other mother's breast milk & 72 & $(11)$ \\
\hline Cow or buffalo milk & 9 & $(1)$ \\
\hline Infant formula & 3 & $(<1)$ \\
\hline Unable to recall & 37 & $(6)$ \\
\hline Total & $\mathbf{6 7 1}$ & $\mathbf{( 1 0 0 )}$ \\
\hline
\end{tabular}

${ }^{1}$ Untrained health worker who conducts delivery in the community

${ }^{2}$ Health assistant, staff nurse, auxiliary health worker, community medical assistant, auxiliary nurse midwife, maternal and child health worker

${ }^{3}$ FCHV: Female community health volunteer; TBA: Trained birth attendant

Table 4: Asphyxial conditions and resuscitation at delivery, for 671 neonatal deaths in 60 village development committees of Dhanusha district, 2006-2008

\begin{tabular}{|l|c|c|}
\hline & Frequency & (\%) \\
\hline Infant cried immediately after birth & & \\
\hline Yes & 395 & $(59)$ \\
\hline No & 276 & $(41)$ \\
\hline Total & $\mathbf{6 7 1}$ & $(\mathbf{1 0 0})$ \\
\hline Time until infant cried, if not immediately & & \\
\hline Within 5 min & 22 & $(8)$ \\
\hline $5-30$ min & 67 & $(25)$ \\
\hline$>30$ min & 44 & $(17)$ \\
\hline Never cried & 132 & $(50)$ \\
\hline Total & $\mathbf{2 6 5}$ & $(\mathbf{1 0 0})$ \\
\hline Resuscitation measures & & \\
\hline Mouth-to-mouth respiration & 111 & $(45)$ \\
\hline Tactile stimulation & 77 & $(31)$ \\
\hline Mouth to tube-and-mask ventilation & 47 & $(19)$ \\
\hline Bag-and-mask ventilation & 13 & $(5)$ \\
\hline Total & $\mathbf{2 4 8}$ & $\mathbf{( 1 0 0 )}$ \\
\hline
\end{tabular}


Table 5: Treatment modalities for 646 neonatal deaths in 60 village development committees of Dhanusha district, $2006-2008$

\begin{tabular}{|l|c|c|}
\hline & Frequency & (\%) \\
\hline Treatment received & & \\
\hline Yes & 281 & $(44)$ \\
\hline No & 365 & $(56)$ \\
\hline Total & $\mathbf{6 4 6}$ & $(\mathbf{1 0 0})$ \\
\hline Treatment given at: & & \\
\hline Hospital & 106 & $(38)$ \\
\hline Other health institute (private clinic, nursing home) & 63 & $(23)$ \\
\hline Home & 75 & $(27)$ \\
\hline Traditional healers (jhankri, herbalists) & 35 & $(12)$ \\
\hline Total & $\mathbf{2 7 9}$ & $\mathbf{( 1 0 0 )}$ \\
\hline
\end{tabular}

Table 6: Comparison of characteristics of 17377 infants who survived and 1272 infants who were stillborn or died in the neonatal period, in 60 village development committees of Dhanusha district, 2006-2008

\begin{tabular}{|c|c|c|c|c|c|}
\hline & & \multicolumn{2}{|c|}{\begin{tabular}{|c|}
$\begin{array}{c}\text { Infants who survived } 28 \text { days } \\
\mathrm{n}=17377\end{array}$ \\
\end{tabular}} & \multicolumn{2}{|c|}{$\begin{array}{c}\begin{array}{c}\text { Stillbirths and perinatal deaths } \\
\mathrm{n}=1272\end{array} \\
\end{array}$} \\
\hline & & Frequency & $(\%)$ & Frequency & $(\%)$ \\
\hline \multirow[t]{3}{*}{ Infant sex } & Male & 9147 & $(53)$ & 713 & $(56)$ \\
\hline & Female & 8230 & $(47)$ & 559 & $(44)$ \\
\hline & Total & 17377 & (100) & 1272 & (100) \\
\hline \multirow[t]{3}{*}{ Maturity } & Term & 17110 & $(99)$ & 970 & $(76)$ \\
\hline & Preterm & 181 & $(1)$ & 302 & $(24)$ \\
\hline & Total & 17291 & (100) & 1272 & (100) \\
\hline \multirow[t]{6}{*}{ Place of delivery } & Home & 14100 & $(82)$ & 826 & $(65)$ \\
\hline & Hospital & 2324 & (14) & 254 & $(20)$ \\
\hline & Other health Institution & 602 & (4) & 145 & (12) \\
\hline & On the way to hospital & 107 & $(<1)$ & 30 & (2) \\
\hline & $\begin{array}{l}\begin{array}{l}\text { Other (including vehicle } \\
\text { delivery) }\end{array} \\
\end{array}$ & 101 & $(<1)$ & 17 & (1) \\
\hline & Total & 17234 & (100) & 1272 & (100) \\
\hline \multirow[t]{8}{*}{ Birth attendant } & Relative & 5607 & (34) & 360 & $(28)$ \\
\hline & Doctor & 1623 & $(10)$ & 341 & $(27)$ \\
\hline & Village practitioner & 978 & (6) & 241 & $(19)$ \\
\hline & Health worker & 2104 & (13) & 161 & (13) \\
\hline & Volunteer & 5159 & $(31)$ & 105 & $(8)$ \\
\hline & No attendant & 500 & (3) & 50 & $(4)$ \\
\hline & $\begin{array}{l}\text { Others (friends, } \\
\text { neighbors) }\end{array}$ & 460 & (3) & 14 & (1) \\
\hline & Total & 16431 & (100) & 1272 & (100) \\
\hline \multirow[t]{3}{*}{$\begin{array}{l}\text { Umbilical cord cutting } \\
\text { implement }\end{array}$} & Unboiled instrument & 10614 & $(66)$ & 345 & (53) \\
\hline & Boiled blade & 4687 & (29) & 118 & (18) \\
\hline & Other & 54 & $(<1)$ & 10 & (1) \\
\hline
\end{tabular}


Table 6 cont..

\begin{tabular}{|c|c|c|c|c|c|}
\hline & Not recalled & 660 & (4) & 180 & $(28)$ \\
\hline & Total & 16015 & (100) & 653 & (100) \\
\hline \multirow[t]{3}{*}{$\begin{array}{l}\text { Infant cried } \\
\text { immediately }\end{array}$} & Yes & 9968 & $(86)$ & 395 & (59) \\
\hline & No & 1627 & (14) & 276 & $(41)$ \\
\hline & Total & 11595 & $(100)$ & 671 & (100) \\
\hline \multirow[t]{6}{*}{$\begin{array}{l}\text { Umbilical cord } \\
\text { application }\end{array}$} & Applied nothing & 5508 & $(35)$ & 240 & $(37$ \\
\hline & Oil & 1986 & $(13)$ & 28 & (4) \\
\hline & Antiseptic (Dettol) & 1435 & (9) & 23 & (3) \\
\hline & Other (dung, ash) & 5637 & $(36)$ & 134 & $(21)$ \\
\hline & Not recalled & 1163 & (7) & 228 & $(35)$ \\
\hline & Total & 15729 & $(\mathbf{1 0 0})$ & 653 & $(\mathbf{1 0 0 )}$ \\
\hline \multirow[t]{9}{*}{ First feed } & No prelacteal & 0 & $(0)$ & 203 & $(30)$ \\
\hline & Goat's milk & 5255 & $(31)$ & 155 & $(23)$ \\
\hline & Mother's breast milk & 4175 & $(24)$ & 80 & $(12)$ \\
\hline & $\begin{array}{l}\text { Other mother's breast } \\
\text { milk }\end{array}$ & 4123 & $(24)$ & 72 & $(11)$ \\
\hline & $\begin{array}{l}\text { Prelacteal (Honey, } \\
\text { sugar, clarified butter ) }\end{array}$ & 3042 & $(18)$ & 112 & $(17)$ \\
\hline & Cow, buffalo milk & 282 & (2) & 9 & $(1)$ \\
\hline & Infant formula & 181 & $(1)$ & 3 & $(<1)$ \\
\hline & Not recalled & 60 & $(<1)$ & 37 & $(6)$ \\
\hline & Total & 17118 & $(100)$ & 671 & (100) \\
\hline \multirow[t]{3}{*}{ Treatment given } & Yes & 8869 & (54) & 365 & $(56)$ \\
\hline & No & 7568 & $(46)$ & 281 & $(44)$ \\
\hline & Total & 16437 & (100) & 646 & (100) \\
\hline
\end{tabular}


Box 1: Classification of stillbirth and neonatal death

\begin{tabular}{|c|c|}
\hline Criteria & Classification \\
\hline Infant did not breathe, cry or move at birth, weighing $>1000 \mathrm{~g}$ or $>28$ weeks & Stillbirth \\
\hline Baby looked swollen, puffy face with skin peeling & Macerated stillbirth \\
\hline $\begin{array}{l}\text { Normal looking baby with skin intact, implying death }<12 \text { hours before delivery, } \\
\text { weighing }>1000 \mathrm{~g}\end{array}$ & Fresh stillbirth \\
\hline $\begin{array}{l}\text { Gross visible malformation, such as meningomyelocele, anencephaly, } \\
\text { gastrochisis }\end{array}$ & Lethal congenital malformation \\
\hline $\begin{array}{l}\text { Prolonged labour }>24 \mathrm{hrs} \text {, bleeding per vaginam, antepartum hemorrhage, } \\
\text { postpartum hemorrhage, cord prolapse, cord around infant's neck, pregnancy } \\
\text { induced hypertension, eclampsia, ruptured uterus, emergency caesarean section, } \\
\text { malpresentation }\end{array}$ & Obstetric complications \\
\hline $\begin{array}{l}\text { Birth weight }<2500 \mathrm{~g} \text { and age }<36 \text { weeks, or pregnancy ended early and infant } \\
\text { was smaller than usual at birth }\end{array}$ & Prematurity \\
\hline $\begin{array}{l}\text { History of chronic illness like Diabetes, Tuberculosis, Rheumatic Heart Disease, } \\
\text { HIV, Epilepsy to mother }\end{array}$ & Maternal disease \\
\hline Twin or triplet & Multiple pregnancy \\
\hline External trauma to mother during pregnancy & Accident or external condition \\
\hline Above conditions not fulfilled and other cause discernible from history & Other \\
\hline Cause could not be ascertained due to lack of information & Unclassifiable \\
\hline Infant breathed, cried or moved at birth, but died before 28 complete days & Neonatal death \\
\hline $\begin{array}{l}\text { Death within } 4 \text { hours of birth or gestational age }>36 \text { weeks and not able to } \\
\text { breathe normally at birth, or not able to suckle normally at birth, convulsions or } \\
\text { spasms, but not tetanus or fever. *Supportive criteria: history of prolonged labour, } \\
\text { malpresentation, twin, very large baby }\end{array}$ & Birth asphyxia \\
\hline $\begin{array}{l}\text { Fever or cold and limp or lethargic or convulsions or bulging fontanel and } \\
\text { refusing to feed and no localizing signs } \\
\text { Duration }>1 \text { day and chest indrawing or difficulty breathing } \\
\text { Umbilical area red or discharging pus or skin red, inflamed or hot or skin rash } \\
\text { with pustules or pus and fever }>1 \text { day } \\
\text { Age } 3-27 \text { days and convulsions or spasms and able to suckle and cry normally } \\
\text { after birth and stopped suckling or crying **Supportive criteria: use of dirty } \\
\text { instruments to cut the cord, red and discharging umbilicus, not completed } \\
\text { tetanus toxoid immunization course }\end{array}$ & Severe infection \\
\hline $\begin{array}{l}\text { Birth weight }<2500 \mathrm{~g} \text { and age }<36 \text { weeks, or pregnancy ended early and infant } \\
\text { was smaller than usual at birth }\end{array}$ & $\begin{array}{l}\text { Prematurity or low birth } \\
\text { weight }\end{array}$ \\
\hline $\begin{array}{l}\text { Especially in winter months and history of having been bathed immediately } \\
\text { after birth }\end{array}$ & Hypothermia \\
\hline $\begin{array}{l}\text { Gross visible malformation, such as meningomyelocele, anencephaly, } \\
\text { gastrochisis }\end{array}$ & Congenital malformation \\
\hline Bruises or marks of injury on body or head at birth & Accident or external condition \\
\hline Above conditions not fulfilled and due to other reasons & Others \\
\hline Cause could not be ascertained due to lack of information & Unclassifiable \\
\hline
\end{tabular}




\section{Discussion}

The commonest cause ascribed to stillbirths was obstetric complications. This may reflect either delay in receiving appropriate obstetric care due to geographical difficulty or poor antepartum and intrapartum obstetric care. The fact that 504 stillbirths (84\%) were fresh suggests that infants might have been viable during labour. Better intrapartum foetal monitoring with timely intervention might reduce the fresh stillbirth rate. Lack of skilled providers in the community could be one reason for the high fresh stillbirth rate. Birth asphyxia was found to be the commonest cause of neonatal death. This also indicates a lack of proper intrapartum monitoring, timely and appropriate intervention and neonatal resuscitation in the community. Indeed, the combination of fresh stillbirths and early neonatal deaths from asphyxia probably reflects the same process ${ }^{28}$. In this study population, $65 \%$ of deliveries were at home and most (59\%) were assisted by untrained persons. This reflects the national scenario in which $80 \%$ of deliveries are conducted by relatives at home ${ }^{29}$.

A verbal autopsy analysis from Egypt found prematurity (39\%), asphyxia (18\%) and infections $(7 \%)$ to be the commonest causes of neonatal deaths ${ }^{30}$. Among perinatal deaths, birth asphyxia was the commonest cause (44\%). In a study in rural Pakistan, the main causes of neonatal death were asphyxial conditions, neonatal sepsis and conditions associated with prematurity ${ }^{31}$. $65 \%$ of neonatal deaths occurred at home and most of the deliveries were conducted by dais (untrained birth attendants). In a study from rural Maharashtra (India), Kulkarni et al found that low birth weight $(36 \%)$ was the main cause of early neonatal deaths, followed by prematurity $(26 \%)^{32}$. Prematurity was the commonest cause of stillbirth, and women under 21 years old were reported as having higher rates of premature delivery.

Few community verbal autopsy studies have been done in Nepal. In Morang district, Khanal et al found that infection (41\%), birth asphyxia (37\%) and prematurity or low birth weight (18.4\%) were common causes of neonatal death ${ }^{33}$. They also found that infection was seen mostly after home deliveries. Wrapping of infants with unclean cloth, cutting the umbilical cord with unsterilised instruments, and birth attendance conducted by relatives, were possible reasons for this. Our study also showed that severe infection was the second most common cause of neonatal death. In as many as $20 \%$ of cases, dung or ash was applied to the umbilical stump. A similar study from Sarlahi district found that birth asphyxia (33\%), serious infection (30\%) and prematurity (29\%) were the commonest causes of neonatal death ${ }^{34}$. This again suggests sub-optimal intrapartum and postnatal care in the community. The study also identified 30 cases of neonatal tetanus, which may have been due to inadequate coverage of tetanus toxoid immunisation and traditional cord care practices.

Our study highlights another important issue. Neonatal deaths caused by infection tend to occur later, while early deaths are more often associated with birth asphyxia ${ }^{35}$. In previous studies, and in global estimates, deaths from infection, preterm and asphyxia have tended to occur at similar rates ${ }^{27,36,37}$. The proportion of neonatal deaths in the first week has tended to be $60-70 \%$. In our study, early neonatal deaths accounted for almost $80 \%$ of neonatal deaths, and asphyxia $41 \%$. This means that asphyxial deaths are becoming the dominant problem, an interpretation that is intuitive in the sense that the numbers of late neonatal deaths are falling. An emphasis on intrapartum care is required, and this fits well with the safer motherhood agenda and recommendations. One worrying issue is the high incidence of oxytocic injection, often delivered in uncontrolled environments. This potentially harmful practice has become common and our finding of a level of $50 \%$ is a cause for concern that supports both anecdotal information about practices in the district and previous research ${ }^{38}$.

\section{Conclusion}

The current high rates of stillbirth and neonatal death in Dhanusha suggest that the quality of care provided during pregnancy and delivery remains sub-optimal. The high rates of stillbirth and asphyxial mortality imply that, while efforts to improve hygiene need to continue, intrapartum care is a priority. A second area for consideration is the need to reduce the uncontrolled use of oxytocics for augmentation of labour.

\section{Acknowledgements}

Thanks are due to all the staff involved in the collection of data in the community, and to the mothers and relatives who agreed to be interviewed in a distressing situation.

\section{References}

1. Population division, Ministry of Health and Population (MOHP), Government of Nepal. Infant and child mortality. In: New ERA and Macro International Inc.eds. NepalDemographic and Health Survey (NDHS) 2006, Kathmandu: Ministry of Health and Population, New ERA, and Macro International Inc: 2007. p.125.

2. Lawn JE, Osrin D, Adler A, et al. Four million neonatal deaths: counting and attribution of cause of death. Paediatr Perinat Epidemiol. 2008;22:410-6. 
3. Garenne M, Fauveau V. Potential and limits of verbal autopsies. Bull WHO. 2006;84: 164-5.

4. Soleman N, Chandramohan D, Shibuya K. Verbal autopsy: current practices and challenges. Bull World Health Organ. 2006.4(3):239-45.

5. Baiden F, Bawan A, Binka R, et al. Setting international standards for verbal autopsy. Bull World Health Organ. 2007;85(8):570-1.

6. Datta N, Kumar V. Validation of causes of infant death in the community by verbal autopsy. Indian J Pediatr. 1988;55:599-604.

7. Kalter H, Gray RH, Black RE, et al. Validation of post-mortem interviews to ascertain selected causes of death in children. Int J Epidemiol. 1990;19: 380-6.

8. Gray R, Smith G, Barrs P. The use of verbal autopsy methods to determine selected causes of death in children. Johns Hopkins University, School of Hygiene and Public Health, Institute of International Programs, 1990. Occasional paper no. 10.

9. Snow RW, Marsh K. How useful are verbal autopsies to estimate childhood causes of death? Health Policy Plan. 1992;7:22-9.

10. Marsh D, Majid N, Rasmussen Z, et al. Causespecific child mortality in a mountainous community in Pakistan by verbal autopsy. J Pak Med Assoc. 1993;43:226-9.

11. Nykanen M,Tamoana W, Cullinan $\mathrm{T}$, et al. Verbal autopsy as a technique to establish causes of infant and child mortality. East Africa Med J. 1995;72:731-4.

12. Mobley CC, Boerma JT, Titus S, et al. Validation study of a verbal autopsy method for causes of childhood mortality in Namibia. Journal of Tropical Pediatrics. 1996;42:365-9.

13. Baqui AH, Black RE, Arifeen SE, et al. Causes of childhood deaths in Bangladesh: results of a nationwide verbal autopsy study. Bull World Health Organ. 1998;76:161-71.

14. Fantahun M. Patterns of childhood mortality in three districts of north Gondar Administrative Zone. A community based study using the verbal autopsy method. Ethiopian Med J. 1998;36:7181.

15. Edmond KM, Quigley MA, Zandoh C, et al. Diagnostic accuracy of verbal autopsies in ascertaining the causes of stillbirths and neonatal deaths in rural Ghana. Paediatr Perinat Epidemiol. 2008;22(5):417.

16. Setel PW, Rao C, Hemed Y, et al. Core verbal autopsy procedures with comparative validation results from two countries. PLoS Med. 2006;3(8):e268.
17. Anker M. The effect of misclassification error on reported cause-specific mortality fractions from verbal autopsy. Int J Epidemiol. 1997;26(5):1090-6.

18. Quigley MA, Chandramohan D, Rodrigues LC. Diagnostic accuracy of physician review, expert algorithms and data-derived algorithms in adult verbal autopsies. Int $\mathrm{J}$ Epidemiol.1999;28(6):1081-7.

19. Freeman JV, Christian P, Khatry SK, et al. Evaluation of neonatal verbal autopsy using physician review versus algorithm-based causeof-death assignment in rural Nepal. Paediatr Perinat Epidemiol. 2005;19(4):323-31.

20. Reeves BC, Quigley M. A review of dataderived methods for assigning causes of death from verbal autopsy data. Int J Epidemiol. 1997;26(5):1080-9.

21. Quigley MA, Chandramohan D, Setel P, et al. Validity of data-derived algorithms for ascertaining causes of adult death in two African sites using verbal autopsy. Trop Med Int Health. 2000;5(1):33-9.

22. Manandhar DS, Osrin D, Shrestha B et al. Effect of a participatory intervention with women's groups on birth outcomes in Nepal. Lancet. 2004;364:970 -9.

23. Sharma NK. Dhanusha. In: SR Joshi eds. District profile of Nepal 2007/2008. 1st edition. Kathmandu: Intensive Study \& Research Centre; $16^{\text {th }}$ September 2007.p. 346- 58.

24. Baseline survey MIRA (Mother and Infant Research Activities) Dhanusha 2006. (Unpublished)

25. Anker M, Black RE, Coldham C, et al. A standard verbal autopsy method for investigating causes of death in infants and children. WHO/ CDS/CSR/ISR/99.4. Geneva: WHO, Johns Hopkins School of Hygiene and Public Health, London School of Hygiene and Tropical Medicine. 1999.

26. Winbo IG, Serenius FH, Dahlquist GG, et al. NICE, a new cause of death classification for stillbirths and neonatal deaths. Int J Epidemiol. 1998;27(3):499-504.

27. Lawn JE, Wilczynska-Ketende K, Cousens SN. Estimating the causes of 4 million neonatal deaths in the year 2000. Int J Epidemiol. 2006;35(3):706-18.

28. Lawn J, Shibuya K, Stein C. No cry at birth: global estimates of intrapartum stillbirths and intrapartum-related neonatal deaths. Bull World Health Organ. 2005;83:409-17. 
29. State of the world's newborns: Nepal. Saving Newborn Lives. Nepal: Save the Children; July 2002.

30. Campbell O, Gipson R, Mohandes AE, et al. The Egypt national perinatal/neonatal mortality study 2000. J Perinatol. 2004;24:284-9.

31. Bhutta ZA, Zahid AM, Zaidi S, et al. A verbal autopsy survey of Perinatal Mortality in rural Pakistan. Pakistan: Child Health and Nutrition Research Initiative (CHNRI); 2004.

32. Kulkarni R, Chauhan S, Shah B, et al. Investigating the causes of perinatal mortality by verbal autopsy in Maharashtra, India. Indian J Commun Med. 2007;32:259-63.

33. Khanal S, Singh V, Dawson P. Verbal autopsy to ascertain the causes of death in neonates at community setting. Presented paper in the $5^{\text {th }}$ Conference of Perinatal Society of Nepal (PESON) 2-3 ${ }^{\text {rd }}$ Dec 2005; Kathmandu, Nepal (Unpublished).
34. Lee AC, Mullany LC, Tielsch JM, et al. Verbal autopsy methods to ascertain birth asphyxia deaths in a community based setting in southern Nepal. Pediatrics. 2008;121(5):e1372- 80.

35. Osrin D, Vergnano S, Costello A. Serious bacterial infections in newborn infants in developing countries. Curr Opin Infect Dis. 2004;17:217-24.

36. Lawn JE, Cousens S, Bhutta ZA, et al. Why are 4 million newborn babies dying each year? Lancet. 2004;364:399-401.

37. Lawn JE, Cousens S, Zupan J, et al. 4 million neonatal deaths: When? Where? Why? Lancet. 2005; 365:891-900.

38. Ellis M, Manandhar N, Manandhar DS, et al. Risk factors for neonatal encephalopathy in Kathmandu, Nepal, a developing country: unmatched case-controlled study. Br Med J. 2000;320:1229-36. 